\title{
Florence Nightingale (1820-1910): maternal mortality and the training of midwives
}

\author{
Peter M Dunn
}

Florence Nightingale was named after her birthplace. She was born on 12 May 1820 while her parents were on the 'Grand Tour'. Her father, William, a wealthy country gentleman who later became High Sheriff of Hampshire, undertook most of her education. She grew to become an attractive, charming, and very talented young woman who was presented to Queen Victoria in 1839. However, she had already determined to devote her life to nursing. At that time nurses and indeed midwives were drawn from the labouring classes, were untrained, and often promiscuous and drunk.

Though her parents protested strongly, she persisted and in 1854 at the age of 34 was chosen by Sidney Herbert, Secretary for War, to lead a team of nurses out to Scutari during the Crimean War. Her powers of organisation and discipline revolutionised both the nursing techniques and conditions at the barrack hospital. Christened 'The Lady with the Lamp' by the wounded solders, she returned home in 1856 a national heroine. A fund was raised by public subscription. This enabled her to found the Nightingale School of Nursing at St Thomas's Hospital in 1860 and, a year later, a training school for midwives at Kings College Hospital, London. Although at first the latter flourished, closure followed a serious outbreak of puerperal sepsis in 1867. This led Miss Nightingale to study the causes of maternal mortality both at home and abroad. She wrote:

'There appears to have been no uniform system of record of deaths, or of causes of death, in many institutions, and no common agreement as to the period after delivery during which deaths should be counted as due to the puerperal condition ... the first step is to enquire, what is the real normal death rate of lying-in women. Compare the rate with the rates in establishments into which parturition cases are received in numbers. Clarify the causes of death and see if any particular cause predominates in lyingin institutions; and if so, why?'

Department of Perinatal Medicine and Child Health, University of Bristol, Southmead Hospital, Bristol BS10 5NB

P M Dunn

Correspondence to: Professor Peter Dunn.
In 1871 Miss Nightingale published her remarkable findings and conclusions in a book entitled Introductory Notes on Lying-in Institutions. ${ }^{1}$

\section{On maternal mortality}

'... with all their defects, midwifery statistics

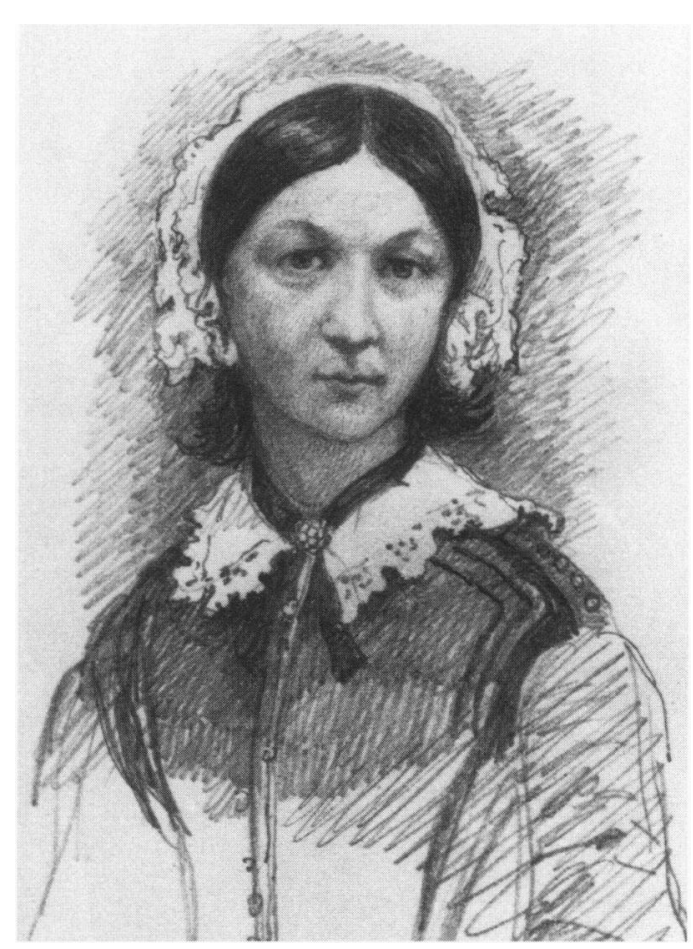

Florence Nightingale, 1857. Portrait by Sir George Scharf, courtesy of the National Portrait Gallery.

point to one truth; namely that there is a large amount of preventable mortality in midwifery practice, and that, as a general rule, the mortality is far, far greater in lyingin hospitals than among women lying-in at home ... for every two women who would die if delivered at home, fifteen must die if delivered in hospital'.

While the maternal mortality might be as low as 2 to 5 per 1000 births in mothers delivered in the home, it was usually between 8 and 35 in hospital. In some institutions on the continent mortality rates of up to 200 were reported. The overwhelming cause of death was puerperal sepsis. Miss Nightingale listed the added risk factors: the prevalence of puerperal fever outside the hospital; the inclusion of midwifery in general hospitals; the proximity of the midwifery wards to the postmortem theatres; the admission of medical students; the failure to isolate cases of puerperal fever; the use of the same staff/bedding; and the want of proper ventilation and cleanliness, including the personal habits of attendants. She recommended that in future lying-in establishments 
should be well situated and isolated from any general hospital or medical school; that the wards should be small and constantly rotated in use; that they should be frequently cleaned with lime washing; that deliveries should be conducted by midwives specially attached to the labour wards; that whenever possible the same birth attendant should look after mother and baby throughout; that there should be early home discharge of the mothers; that cases of puerperal fever should be immediately isolated; and that there should be a reduction of intercommunication between lying-in and hospital divisions (medical officers and nurses).

Miss Nightingale then went on to discuss the urgent need for skilled birth attendants:

\section{On the training of midwives:}

'While all that we women think about is to have the same education as men in medicine, must we not feel the women's medical movement to be rather barren when it might be so fruitful. Here is a branch so entirely their own, that we may safely say that no lying-in would be attended but by a woman if a woman were as skilful as a man - a physician-accoucheur ... Although every woman would prefer a woman to attend upon her in her lying-in, and in diseases peculiar to her and her children, yet the woman does not exist, or hardly exists, to do it. Midwives are so ignorant that it is almost a term of contempt. Surely it is the first object to enable women, by the most thorough training, practical and scientific, to practice that branch of the art of medicine which all are agreed should be theirs ... as physician accoucheuses; that is to attend and to be consulted in all deliveries, abnormal as well as normal, (and) in disease of women and children ... There must be first, of course, the lying-in institution, the deliveries conducted by fully qualified head midwives ... There must be a staff of professors to give scientific instruction in midwifery, but also in anatomy, physiology, pathology and above all in sanitary science. Dissections and postmortem examinations will have to be practised ... The course ... must certainly not be less than two years'.

Although Florence Nightingale lived in a man's world, she never felt handicapped by her gender or wished to be a man. Sexual equality meant little to her and she had no time for sex antagonism or rivalry. She wrote: 'I am brutally indifferent to the wrongs or rights of my sex'. There was a job to be done. It concerned women. Why not educate them properly in a task that was of such fundamental importance to their lives? Sadly, her visionary thinking for midwifery was neglected for many years, and even now has yet to be fully realised.

Florence Nightingale must rank as one of the great reformers of Victorian England. She created the modern profession of nursing, stamping it with her own characteristics of strength, a caring nature, unselfishness, and a disregard for considerations of class or sex. It was no fault of hers that she failed to achieve the same for midwifery. Then, at a time when the observations of Semmilweis were still not widely known or accepted, she saw clearly how to combat puerperal sepsis. But her achievements ranged far wider into subjects such as reform of the army medical service, hygiene and sanitation, hospital design, care in the home and in the community, health visiting and district nursing, and all aspects of social life in India, advocating in particular the need for native education and village sanitation. She was sought out and consulted by royalty, by viceroys, ministers and even by foreign governments. Yet she was very self-effacing. Often in poor health she drove herself on, working for many years from her bedroom. The secret of her success lay in her organisational skills, her industriousness and knowledge, her clarity of mind, her analytical skills and powers of deduction. These qualities, combined with her altruism, charm, powers of persuasion, and her steely and uncompromising determination, usually succeeded in eventually overcoming any opposition.

In her prime Florence was a very feminine, graceful, vital and strikingly good looking young woman, much admired by men. Indeed, she declined several proposals of marriage. Her sense of duty to serve mankind ruled out such personal considerations. She lived on to the age of 90, much respected and loved. In 1907 King Edward VII presented her with the Order of Merit (the first woman to receive this honour), and in 1908 she was given the freedom of the City of London. Honours also came from Germany, France, Norway and the United States. Her old age was happy and peaceful. The jubilee of the founding of the Florence Nightingale Training School for Nurses took place in May 1910. Death came three months later and she was buried in the family grave at East Wellow. ${ }^{2}$

Nightingale F. Introductory notes on lying-in institutions. London: Longmans, Green, \& Co, 1971: 105-10.

2 Woodham-Smith. Florence Nightingale 1820-1910. Edinburgh: Constable and the Book Society, 1950. 